\title{
Divergent pheromone-mediated insect behaviour under global atmospheric change
}

\author{
EDWARD B. MONDOR, MICHELLE N. TREMBLAY, CAROLINES. AWMACK and RICHARD \\ L. LINDROTH \\ Department of Entomology, University of Wisconsin, Madison, WI 53706, USA
}

\begin{abstract}
While the effects of global atmospheric changes on vegetation and resulting insect populations('bottom-up interactions') are being increasingly studied, how these gases modify interactions among insects and their natural enemies ('top-down interactions') is less clear. As natural enemy efficacy is governed largely by behavioural mechanisms, altered prey finding and prey defence may change insect population dynamics. Here we show that pheromone-mediated escape behaviours, and hence the vulnerability of insects to natural enemies, are divergent under atmospheric conditions associated with global climate change. Chaitophorus stevensis, a common aphid on trembling aspen trees, Populus tremuloides, have diminished escape responses in enriched carbon dioxide $\left(\mathrm{CO}_{2}\right)$ environments, while those in enriched ozone $\left(\mathrm{O}_{3}\right)$ have augmented escape responses, to alarm pheromone. These results suggest that divergent pheromonemediated behaviours could alter predator-prey interactions in future environments.
\end{abstract}

Keywords: air pollution, atmospheric change, bottom-up, carbon dioxide, greenhouse gas, ozone, pheromone, predator-prey, top-down

Received 15 March 2004; revised version received 23 April 2004 and accepted 5 May 2004

\section{Introduction}

Carbon dioxide $\left(\mathrm{CO}_{2}\right)$ and tropospheric ozone $\left(\mathrm{O}_{3}\right)$ levels have increased $31 \%$ and $35 \%$, respectively, since the mid-1800s (IPCC, 2001). Vegetative growth responses of forest and agricultural plants to $\mathrm{CO}_{2}$ and $\mathrm{O}_{3}$ have been well studied, with the consensus emerging that elevated $\mathrm{CO}_{2}$ and $\mathrm{O}_{3}$ levels are stimulatory and inhibitory, respectively (Saxe et al., 1998; Ceulemans et al., 1999; Karnosky et al., 2003). As elevated concentrations of these gases also alter the nutritional and defensive characteristics of plants, their effects can cascade through ecosystems and impact higher trophic levels, such as insect herbivores and their natural enemies (Percy et al., 2002). Chewing insects, such as lepidopteran larvae, generally respond to nutrient dilution in $\mathrm{CO}_{2}$-enriched foliage by increasing consumption, typically resulting in no change or modest decreases in growth (Lindroth, 1996; Bezemer \& Jones, 1998; Coviella \& Trumble, 1999). Performance of the same insects may improve under elevated $\mathrm{O}_{3}$ (Kopper \& Lindroth,

Correspondence: Edward Mondor, Department of Entomology, University of Wisconsin, Madison, WI 53706; fax + 608262 3322, e-mail: mondor@entomology.wisc.edu
2003). Sucking insects, such as aphids, however, are variable in their responses to plants grown under elevated $\mathrm{CO}_{2}$ and $\mathrm{O}_{3}$ (Holopainen, 2002).

In contrast to plant-mediated ('bottom-up') effects on insect herbivores, we know exceedingly little about natural enemy-mediated ('top-down') effects under changing atmospheric conditions (Hunter, 2001). Initial reports suggest that parasitoids and predators are more abundant and/or efficacious under elevated $\mathrm{CO}_{2}$ levels (Stiling et al., 1999; Percy et al., 2002), but are negatively affected by elevated $\mathrm{O}_{3}$ (Gate et al., 1995; Percy et al., 2002). While the mechanisms resulting in altered natural enemy efficacy under changing climactic conditions are unknown, behavioural responses by both natural enemies (e.g. host finding) and pest insects (e.g. prey dispersal) are recognized as important for understanding predatorprey population dynamics (Hassell, 1978; Mangel \& Roitberg, 1992). Indeed, top-down processes are believed to be a key determinant for population sizes of insects that have a high predation risk and limited escape/ defensive behaviours (Denno et al., 2003). Thus, discerning whether insect behaviours may be altered in response to changing atmospheric conditions is critically important for elucidating the mechanisms likely to underlie changes in insect populations in future environments. 
Here we describe a field experiment, investigating the effects of elevated levels of $\mathrm{CO}_{2}$ and $\mathrm{O}_{3}$ on pheromonemediated dispersal behaviour of the phloem-feeding aphid, Chaitophorus stevensis. As aphids are sedentary, group-feeding insects, a principal anti-predator defence is clone-mate dispersal in response to alarm pheromone emission to areas with lower predation risk (Kislow \& Edwards, 1972; Mondor et al., 2000). By measuring aphid dispersal rates, we assess whether pheromonemediated behaviours may be altered under future atmospheric conditions.

\section{Materials and methods}

\section{Field site and gas treatments}

The Aspen Free-Air $\mathrm{CO}_{2}$ Enrichment (FACE) site, consisting of $12,30 \mathrm{~m}$ diameter rings, is located near Rhinelander, WI, USA ( $45.7^{\circ}$ latitude, $89.7^{\circ}$ longitude). The 32 ha site was constructed, and trees planted inside each ring, in 1997. Each FACE ring is divided by a walkway system into three sectors: (1) mixed trembling aspen (Populus tremuloides Michx.) genotypes, (2) trembling aspen and sugar maple (Acer saccharum Marsh.), and (3) trembling aspen and paper birch (Betula papyrifera Marsh.). These stands have been exposed to ambient or elevated levels of $\mathrm{CO}_{2}$ and/or $\mathrm{O}_{3}$ from 1998 until present. The experiment consists of a randomized complete block design of three blocks of four treatments: (1) control $\left(367 \pm 15 \mu \mathrm{LL}^{-1} \mathrm{CO}_{2}\right.$ and $\left.38 \pm 13 \mathrm{~nL} \mathrm{~L}^{-1} \mathrm{O}_{3}\right)$ ，(2) elevated $\mathrm{CO}_{2}\left(+\mathrm{CO}_{2}, 537 \pm\right.$ $\left.77 \mu \mathrm{L} \mathrm{L}^{-1}\right)$, (3) elevated $\mathrm{O}_{3}\left(+\mathrm{O}_{3}, 51 \pm 22 \mathrm{~nL} \mathrm{~L}^{-1}\right)$ and (4) elevated $\mathrm{CO}_{2}$ and $\mathrm{O}_{3}\left(+\mathrm{CO}_{2}+\mathrm{O}_{3}, \quad 537 \pm\right.$ $77 \mu \mathrm{LL}^{-1}+51 \pm 22 \mathrm{nLL}^{-1}$, respectively). $\mathrm{CO}_{2}$ levels are elevated to represent levels predicted for 2060, while $\mathrm{O}_{3}$ levels follow a diurnal pattern based on $\mathrm{O}_{3}$ readings currently experienced in urban areas of the southwestern Great Lakes region of the USA (Dickson et al., 2000). A computer-controlled trace gas monitoring system continually adjusts the ambient and elevated concentrations of gases delivered to forest stands through vertical vent pipes surrounding each ring.

\section{Insect behaviour bioassays}

Experiments were conducted on young C. stevensis colonies, feeding on trembling aspen leaves. These young aphid colonies had developed within the respective gas treatments, as colonies were composed entirely of (wingless) apterous individuals except for the winged (alate) individuals initiating the colonies, and were typical of early season colonies, being widely dispersed both within and among trees. Furthermore,
C. stevensis have limited dispersal, remaining on trees within individual FACE rings (Percy et al., 2002).

Individual aspen leaves, containing a single aphid colony ( $25 \pm 2$ aphids), were carefully abscised from the tree and held in the same orientation as when on the tree (i.e. adaxial side up). Removing the leaf allowed careful observation of all aphids on the leaf, which was not possible directly on the tree, because of the 'trembling' of the leaves. Prior to applying one of two treatments, which were assigned at random using paper chits, to a particular colony, the numbers of each aphid developmental stage (first, second instars; third, fourth instars; and adults) in the colony were counted. After the initial count, an apterous aphid in the colony was selected at random for one of the following treatments: (1) no alarm pheromone (control) (an aphid was prodded lightly on the thorax, so as to not produce a visible pheromone droplet) or (2) alarm pheromone (treatment) (an aphid was prodded more heavily on the thorax and induced to emit a visible pheromone droplet) (Mondor \& Roitberg, 2003).

Arboreal aphids seldom drop from their feeding sites, because of an inability to regain such sites thereafter. Consequently, aphids exhibiting any dispersal reactions in response to pheromone emission as well as those exhibiting the most extreme dispersal response, walking down the petiole and off the leaf, were recorded over $5 \mathrm{~min}$. As recorded, these two behaviours are not mutually exclusive, i.e. aphids dispersing off the leaf are also included in the general dispersal response category. We chose not to make these categories mutually exclusive; so that we could better compare the effect of altered atmospheric conditions on total vs. extreme dispersal responses. Five minutes were chosen because aphid alarm pheromone has the largest effect on aphid colonies during the first few minutes following emission (Montgomery \& Nault, 1977). Five subsamples of each treatment $(n=5$ droplets, 5 no droplets) per ring $(n=12$ rings) were conducted ( $n=120$ total). Aphid colonies were always selected from different trees and used just once during the experiment. Bioassays were conducted from 09:00 to 16:00 hours, inside treatment rings.

\section{Statistical analyses}

As individual assays within each FACE ring were subsamples rather than true replicates, and because subsamples contained different numbers of aphids, overall proportions of aphids of each developmental stage (first, second instar; third, fourth instar; and adults) dispersing in response to alarm pheromone were calculated. These proportions were obtained by dividing the total number of dispersers by the total 
number of aphids, summed across the five subsamples for each treatment for each ring. These proportions were then transformed $\left(x^{\prime}=\arcsin \sqrt{ } x\right)$ to achieve normality (Zar, 1984). As aphid responses to the no pheromone (control) treatment were extremely low $(6.1 \pm 2.1 \%)$ across all gas levels, we removed this treatment from the analysis to better clarify the effects of aphid dispersal in response to alarm pheromone. Data were subsequently analysed using two, three factor split-plot ANOVAs (JMP IN 5.1, SAS Institute, 2005). The two whole-plot factors were $\mathrm{CO}_{2}$ and $\mathrm{O}_{3}$ (fully crossed) with ring block incorporated as a random blocking variable (Dickson et al., 2000). Aphid developmental stage (first, second instar; third, fourth instar; and adults) was incorporated as a subplot factor, within gas treatments. All interactions between $\mathrm{CO}_{2}$, $\mathrm{O}_{3}$, and aphid developmental stage were incorporated into the model as subplot interactions. The response variables in the two analyses were the proportion of aphids: (1) exhibiting any dispersal responses and (2) dispersing entirely from the leaf, in response to alarm pheromone emission.

\section{Results}

Pooled across instars, aspen aphids showed divergent responses to alarm pheromone under elevated $\mathrm{CO}_{2}$ and $\mathrm{O}_{3}$. Significantly fewer aphids exhibited any dispersal responses $\left(F_{1,8}=9.45, P=0.015\right)$ or dispersed entirely from the leaf $\left(F_{1,8}=10.11, P=0.013\right)$, in response to alarm pheromone under elevated $\mathrm{CO}_{2}$ relative to ambient $\mathrm{CO}_{2}$ (Figs 1 and 2). Conversely, elevated concentrations of $\mathrm{O}_{3}$ increased dispersal responses to alarm pheromone, both in total $\left(F_{1,8}=21.16, P=0.002\right)$ and from the leaf itself $\left(F_{1,8}=28.61, P<0.001\right)$ (Figs 1 and 2). There were no significant $\mathrm{CO}_{2} \times \mathrm{O}_{3}$ interactions for either general dispersal $\left(F_{1,8}=0.49, P=0.74\right)$ or dispersal from the leaf $\left(F_{1,8}=1.40, P=0.27\right)$.

Pooled across gas treatments, neither total dispersal $\left(F_{2,16}=1.66, P=0.22\right)$ nor dispersal from the leaf $\left(F_{2,16}=1.90, P=0.18\right)$ differed by instar. Similarly, though adult aphids appeared to respond much less under augmented $\mathrm{CO}_{2}$ concentrations, we observed no instar $\times \mathrm{CO}_{2}$ interactions (total dispersal, $F_{2,16}=1.29$, $P=0.30$; dispersal from leaf, $F_{2,16}=1.46, P=0.26$ ) or instar $\times \mathrm{CO}_{2} \times \mathrm{O}_{3}$ interactions (total dispersal, $F_{2,16}=2.69, \quad P=0.099$; dispersal from leaf, $\left.F_{2,16}=0.049, P=0.95\right)$, for either type of dispersal. There were, however, significant instar $\times \mathrm{O}_{3}$ interactions for both total dispersal $\left(F_{2,16}=10.22, P=0.001\right)$ and dispersal from the leaf $\left(F_{2,16}=18.10, P=0.0001\right)$. Dispersal behaviour did not differ appreciably in immature instars under atmospheres containing ambient vs. enriched levels of $\mathrm{O}_{3}$ (control and $+\mathrm{CO}_{2}$ vs.

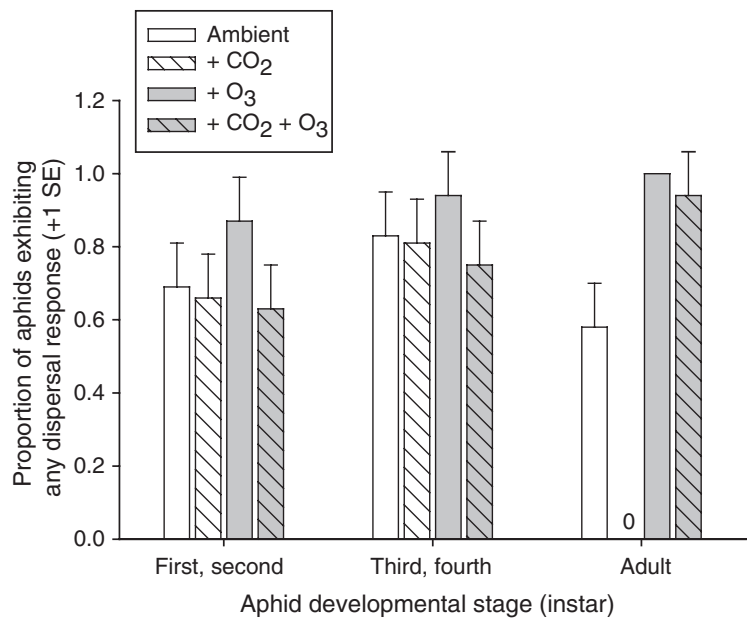

Fig. 1 Proportions of three aphid developmental stages exhibiting any dispersal responses in response to aphid alarm pheromone emission (means $+1 \mathrm{SE}$ ). See text for detailed explanations of significant effects.

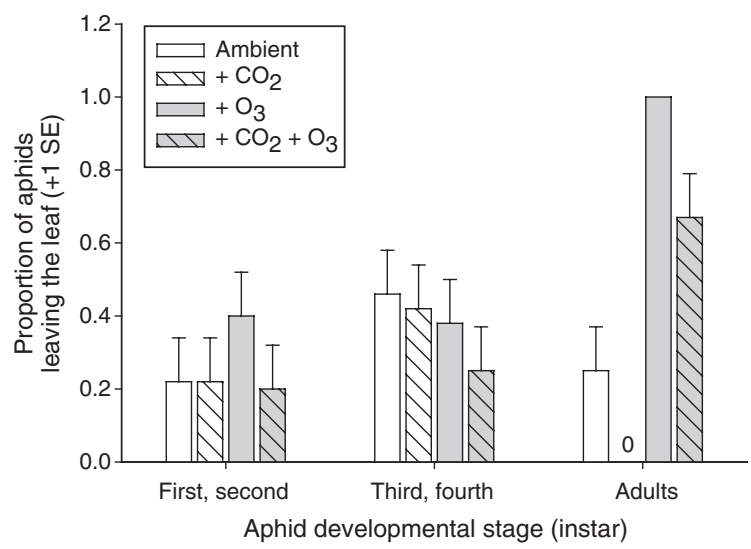

Fig. 2 Proportions of three aphid developmental stages dispersing from the leaf in response to aphid alarm pheromone emission (means $+1 \mathrm{SE}$ ). See text for detailed explanations of significant effects.

$+\mathrm{O}_{3}$ and $+\mathrm{CO}_{2}+\mathrm{O}_{3}$ treatments), but was vastly divergent in adults. In fact, $0 \%$ of adults dispersed from the leaf under $+\mathrm{CO}_{2}$ while $100 \%$ dispersed under $+\mathrm{O}_{3}$ (Figs 1 and 2).

\section{Discussion}

Pheromones are utilized by insects for several purposes, including alarm signalling (Kislow \& Edwards, 1972; Blatt et al., 1998; Hunt et al., 2003), kin recognition (Dani et al., 2001; VanderMeer \& Alonso, 2002), and sexual communication (Pickett et al., 1992; Landolt \& Phillips, 1997). The prevalence of chemical communication among organisms makes it imperative that we 
understand how these chemical signals may be altered under atmospheric conditions that contribute to global climate change. Here, we showed that the principal means of defence for aphids, dispersal responses to alarm pheromone, decreases under elevated $\mathrm{CO}_{2}$ but increases under elevated $\mathrm{O}_{3}$. Thus, intraspecific olfactory communication may be radically altered in response to elevated concentrations of different greenhouse gases.

Divergent defensive behaviours in response to elevated levels of $\mathrm{CO}_{2}$ and $\mathrm{O}_{3}$ may, at least partially, contribute to altered insect population dynamics. As adults are more strongly affected by changing $\mathrm{O}_{3}$ concentrations than are immature aphids, it is tempting to speculate that greater numbers of $C$. stevensis commonly observed under elevated $\mathrm{O}_{3}$ (Percy et al., 2002) are attributable to increased adult defensive behaviour. Population sizes of insects that are sedentary and group-living are often determined by the abundance and efficacy of natural enemies (Walker \& Jones, 2001; Denno et al., 2003). Thus, augmented or reduced escape/defensive behaviours under changing atmospheric conditions may, along with other contributing factors, culminate in altered abundances and spatial distributions of pest insects.

Thus far, the mechanism resulting in differential dispersal responses to alarm pheromone under altered atmospheric conditions remains unknown. There are undeniable changes in host plant quality within different gas treatments, and aphid dispersal is a well-known trade-off between predation risk and host plant quality (Dill et al., 1990; Losey \& Denno, 1998). Glasshouse experiments, however, suggest that an altered ability of aphids to produce and/or respond to alarm pheromone may contribute to altered defensive behaviours under changing climactic scenarios (Awmack et al., 1997). Preliminary evidence also suggests that exposure to atmospheric pollutants, such as $\mathrm{O}_{3}$, can rapidly destabilize pheromone structure and resulting activity (Arndt, 1995). Intriguingly, in our experiment aphids exhibited increased dispersal responses to alarm pheromone under elevated $\mathrm{O}_{3}$. Perhaps pheromone degradation was not a factor in our experiment because of the short-term nature of alarm pheromone activity. Atmospheric pollutants likely alter insect behaviour through a variety of factors including altered host plant quality, pheromone quality/quantity, and pheromone reception.

In summary, the existence of divergent pheromonemediated behaviours in insects under conditions of global atmospheric change could have substantial implications not just from an ecological perspective, but also for how insect-derived compounds are used in pest management programmes. Understanding how global atmospheric change will enhance or negate not only bottom-up but also top-down effects on insect behaviour will vastly improve our ability to predict shifts in insect population dynamics and community interactions in future environments.

\section{Acknowledgements}

Aspen FACE is principally supported by the Office of Science (BER), US Department of Energy, Grant No. DE-FG0295ER62125, the US Forest Service Northern Global Change Program and North Central Research Station, Michigan Technological University, and Natural Resources Canada - Canadian Forest Service. This research was funded by NSF award DEB0129123. We thank site-operators Wendy Jones and Jaak Sober for their help at Aspen FACE, and three anonymous reviewers whose comments substantially improved the manuscript.

\section{References}

Arndt U (1995) Air pollutants and pheromones - a problem. Chemosphere, 30, 1023-1031.

Awmack CS, Woodcock CM, Harrington R (1997) Climate change may increase vulnerability of aphids to natural enemies. Ecological Entomology, 22, 366-368.

Bezemer TM, Jones TH (1998) Plant-insect herbivore interactions in elevated atmospheric $\mathrm{CO}_{2}$ : quantitative analyses and guild effects. Oikos, 82, 212-222.

Blatt SE, Borden JH, Pierce HD et al. (1998) Alarm pheromone system of the western conifer seed bug, Leptoglossus occidentalis. Journal of Chemical Ecology, 24, 1013-1031.

Ceulemans R, Janssens IA, Jach ME (1999) Effects of $\mathrm{CO}_{2}$ enrichment on trees and forests: lessons to be learned in view of future ecosystem studies. Annals of Botany, 84, 577-590.

Coviella CE, Trumble JT (1999) Effects of elevated atmospheric carbon dioxide on insect-plant interactions. Conservation Biology, 13, 700-712.

Dani FR, Jones GR, Destri S et al. (2001) Deciphering the recognition signature within the cuticular chemical profile of paper wasps. Animal Behaviour, 62, 165-171.

Denno RF, Gratton C, Dobel H et al. (2003) Predation risk affects relative strength of top-down and bottom-up impacts on insect herbivores. Ecology, 84, 1032-1044.

Dickson RE, Lewin KF, Isebrands JG et al. (2000) Forest atmosphere carbon transfer storage-II (FACTS II) - the aspen free-air $\mathrm{CO}_{2}$ and $\mathrm{O}_{3}$ enrichment (FACE) project: an overview. USDA Forest Service North Central Research Station General Technical Report NC-214.

Dill LM, Fraser AHG, Roitberg BD (1990) The economics of escape behaviour in the pea aphid, Acyrthosiphon pisum. Oecologia, 83, 473-478.

Gate IM, McNeill S, Ashmore MR (1995) Effects of air pollution on the searching behaviour of an insect parasitoid. Water, Air and Soil Pollution, 85, 1425-1430.

Hassell MP 1978 The Dynamics of Arthropod Predator-Prey Systems. Princeton University Press, Princeton, NJ, USA.

Holopainen JK (2002) Aphid response to elevated ozone and $\mathrm{CO}_{2}$. Entomologia Experimentalis et Applicata, 104, 137-142. 
Hunt GJ, Wood KV, Guzman-Novoa E et al. (2003) Discovery of 3-methyl-2-buten-1-yl acetate, a new alarm component in the sting apparatus of Africanized honeybees. Journal of Chemical Ecology, 29, 453-463.

Hunter MD (2001) Effects of elevated atmospheric carbon dioxide on insect-plant interactions. Agricultural and Forest Entomology, 3, 153-159.

IPCC (2001) Climate change 2001: the scientific basis. Report of Working Group I of the Intergovernmental Panel on Climate Change. IPCC Secretariat, Geneva.

Karnosky DF, Zak DR, Pretziger KS et al. (2003) Tropospheric $\mathrm{O}_{3}$ moderates responses of temperate hardwood forests to elevated $\mathrm{CO}_{2}$ : a synthesis of molecular to ecosystem results from the Aspen FACE project. Functional Ecology, 17, 289-304.

Kislow CJ, Edwards LJ (1972) Repellent odour in aphids. Nature, 235, 108-109.

Kopper BJ, Lindroth RL (2003) Effects of elevated carbon dioxide and ozone on the phytochemistry of aspen and performance of an herbivore. Oecologia, 134, 95-103.

Landolt PJ, Phillips TW (1997) Host plant influences on sex pheromone behaviour of phytophagous insects. Annual Review of Entomology, 42, 371-391.

Lindroth RL (1996) $\mathrm{CO}_{2}$-mediated changes in tree chemistry and tree-Lepidoptera interactions. In: Terrestrial Ecosystem Response to Elevated Carbon Dioxide (eds Koch GW, Mooney HA), pp. 105-120. Academic Press, San Diego.

Losey JE, Denno RF (1998) The escape response of pea aphids to foliar-foraging predators: factors affecting dropping behaviour. Ecological Entomology, 23, 53-61.

Mangel M, Roitberg BD (1992) Behavioural stabilization of hostparasite population dynamics. Theoretical Population Biology, 42, 308-320.
Mondor EB, Baird DS, Slessor KN et al. (2000) Ontogeny of alarm pheromone secretion in the pea aphid, Acyrthosiphon pisum. Journal of Chemical Ecology, 26, 2875-2882.

Mondor EB, Roitberg BD (2003) Age-dependent fitness costs of alarm signaling in aphids. Canadian Journal of Zoology, 81, 757-762.

Montgomery ME, Nault LR (1977) Comparative response of aphids to the alarm pheromone, (E)-beta-farnesene. Entomologia Experimentalis et Applicata, 22, 236-242.

Percy KE, Awmack CS, Lindroth RL et al. (2002) Altered performance of forest pests under atmospheres enriched by $\mathrm{CO}_{2}$ and $\mathrm{O}_{3}$. Nature, 420, 403-407.

Pickett JA, Wadhams LJ, Woodcock CM et al. (1992) The chemical ecology of aphids. Annual Review of Entomology, 37, 67-90.

SAS Institute Inc. (2005) JMP Start Statistics, 3rd edn. Brooks/ Cole - Thomson, Belmont, CA.

Saxe H, Ellsworth DS, Heath J (1998) Tree and forest functioning in an enriched $\mathrm{CO}_{2}$ atmosphere. New Phytologist, 139, 395-436.

Stiling P, Rossi AM, Hungate B et al. (1999) Decreased leafminer abundance in elevated $\mathrm{CO}_{2}$ : reduced leaf quality and increased parasitoid attack. Ecological Applications, 9, 240-244.

VanderMeer RK, Alonso LE (2002) Queen primer pheromone affects conspecific fire ant (Solenopsis invicta) aggression. Behavioral Ecology and Sociobiology, 51, 122-130.

Walker M, Jones TH (2001) Relative roles of top-down and bottom-up forces in terrestrial tritrophic plant-insect herbivore-natural enemy systems. Oikos, 93, 177-187.

Zar JH (1984) Biostatistical Analysis, $2^{\text {nd }} E d n$. Prentice-Hall, Englewood Cliffs, NJ. 